\title{
Comparação da microscopia digital com a microscopia de luz convencional na gradação da displasia epitelial bucal
}

\author{
Ledyane da Silva Mafra (IC), Priscilla Barbosa Diniz (PG), Andreia Aparecida da Silva (PQ), Pablo \\ Agustin Vargas (PQ), Oslei Paes de Almeida (PQ), Marcondes Sena-Filho (PQ), Jacks Jorge (PQ)
}

\section{Resumo}

Este estudo objetivou comparar a eficiência e a acurácia da microscopia digital com a microscopia de luz convencional na gradação da displasia epitelial bucal, usando o sistema de classificação proposto pela OMS. Dois observadores independentes fizeram a seleção de 31 casos, buscando incluir casos de todos os tipos de alterações epiteliais bucais. Os casos foram submetidos a três observadores usando ambos os métodos microscópios. A comparação das variações foram feitas intra e interobservadores.

Palavras Chave: Patologia bucal, Microscopia Digital, Microscopia Convencional de Luz

\section{Introdução}

A microscopia digital é utilizada em patologia para educação, fins de diagnóstico (reuniões clinicopatológicas, consultas, revisões, painéis de slides e, cada vez mais, para diagnósticos clínicos iniciais) e arquivamento ${ }^{1,2,3}$. Não há estudos que busquem comparar a microscopia digital com a microscopia convencional na gradação das displasias epiteliais bucais.

Este estudo objetivou a comparação da microscopia digital com a microscopia de luz convencional na gradação da displasia epitelial bucal, utilizando-se do sistema de gradação de displasia epitelial proposto pela OMS. Três patologistas observadores experientes em patologia bucal avaliaram os casos.

\section{Resultados e Discussão}

Tabela 1. Média de tempo total de análise

\begin{tabular}{|c|c|c|c|}
\hline $\begin{array}{c}\text { Observadores } \\
\text { (anos de experiência) }\end{array}$ & $\begin{array}{l}\text { Microscopia } \\
\text { de Luz }\end{array}$ & $\begin{array}{l}\text { Microscopia } \\
\text { Digital }\end{array}$ & Média \\
\hline$\# 1$ (18) & $3,6 \mathrm{~min}$ & $6,3 \mathrm{~min}$ & $4,9 \mathrm{~min}$ \\
\hline \#2 (26) & $21,7 \mathrm{~min}$ & $20,5 \mathrm{~min}$ & $21,1 \mathrm{~min}$ \\
\hline$\# 3(10)$ & $5,7 \mathrm{~min}$ & $9,5 \mathrm{~min}$ & $7,6 \mathrm{~min}$ \\
\hline Média & $10,3 \mathrm{~min}$ & $15,3 \mathrm{~min}$ & \\
\hline
\end{tabular}

Tabela 2. Variabilidade interobservadores

\begin{tabular}{|c|c|c|}
\multirow{2}{*}{ Observadores } & \multicolumn{2}{|c|}{ Concordância } \\
\cline { 2 - 3 } & Microscopia de Luz & Microscopia Digital \\
\hline \#1 vs \#2 & Razoável & Razoável \\
\hline \#1 vs \#3 & Fraca & Fraca \\
\hline \#2 vs \#3 & Fraca & Fraca \\
\hline
\end{tabular}

Tabela 3. Variabilidade intraobservadores

\begin{tabular}{|c|c|c|}
\multirow{2}{*}{ Observadores } & \multicolumn{2}{|c|}{ Concordância } \\
\cline { 2 - 3 } & Microscopia de Luz & Microscopia Digital \\
\hline$\# 1$ & Moderada & Moderada \\
\hline$\# 2$ & Razoável & Razoável \\
\hline$\# 3$ & Razoável & Razoável \\
\hline
\end{tabular}

A variabilidade intra e interobservadores, quando comparados os diagnósticos obtidos inter e intraferramentas, seguiu o mesmo padrão, variando entre fraca a moderada. Houve também similaridade nas variações, evidenciando que os diagnósticos obtidos pela microscopia digital são semelhantes aos da microscopia convencional de luz. Tal fato sugere que a microscopia digital pode propiciar detalhes microscópicos semelhantes à microscopia de luz convencional.

Conclusões

- O grau de variabilidade intra e interobservadores é semelhantes nas duas ferramentas

- Os observadores demandaram mais tempo para análise com microscopia digital

\section{Agradecimentos}

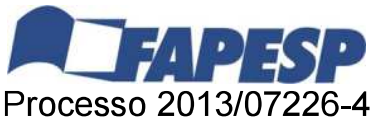

\footnotetext{
${ }^{1}$ Krenacs T, Zsakovics I, Micsik T, Fonyad L, Varga SV, Ficsor L, et al. Microscopy: Science, Technology, Applications and Education. In: Méndez-Vilas A, Díaz J, editors. Digital microscopy - the upcoming revolution in histopathology teaching, diagnostics, research and quality assurance. Badajoz: FORMATEX; 2010. p. 96577.

${ }^{2}$ Al-Janabi S, Huisman A, Van Diest PJ. Digital pathology: current status and future perspectives. Histopathology. 2012 Jul;61(1):1-9.
} 